\title{
TEMPERATURE DEPENDENT SEASONAL VARIATION OF THE BACKGROUND IN COUNTERS USED FOR RADIOCARBON DATING
}

\author{
SÖREN HÅKANSSON \\ Radiocarbon Dating Laboratory, Department of Quaternary Geology, \\ University of Lund, Sweden
}

ABSTRACT. All background values measured in one of our ${ }^{14} \mathrm{C}$ counters during 1977 were analyzed together with corresponding values for atmospheric pressure, outdoor temperature, and coincidence counting rate for investigation of the possibilities to separate the temperature dependency of the background from the better known atmospheric pressure dependency.

The background values were normalized to a common atmospheric pressure and plotted in a time diagram. A seasonal trend with higher background values in winter than in summer shown by this diagram was confirmed by regression analysis.

The regression line and the "Standard error of estimate" was calculated for the background values as a function of the atomspheric pressure, on the one hand and as a function of the coincidence counting rate, on the other hand. A comparison showed that the coincidence counting rate in this case was a better parameter than the atmospheric pressure for calculation of the actual background.

The approximate consistency of the temperature effects on the background was checked for the years 1976 to 1978 .

It is well known that the muon intensity at sea level depends on the atmospheric pressure. It is less well known that there are also temperature effects influencing this intensity (Ehmert, 1962, p 356; Cranshaw, 1963, p 95). Since the muons may be responsible for a considerable part of the background in low-level counters (see, for example, Grootes, 1977, p 95), it is reasonable to expect that the background counting rate is also influenced to some extent by the above mentioned temperature effects on the muon intensity.

In order to investigate the possibilities of separating the temperature dependency of the background from the atmospheric pressure dependency, all background values (B) measured in one of our ${ }^{14} \mathrm{C}$ counters during 1977 were analyzed together with corresponding values for coincidence counting rate $\left(\mathrm{N}_{\mathrm{CC}}\right)$, atmospheric pressure $(\mathrm{b})$, and "mean" outdoor temperature $\left[t=\left(t_{\max }+t_{\min }\right) / 2\right]$ during the measurements.

First, the temperature dependent seasonal variation of the coincidence counting rate was checked. An approximate correction factor for the temperature variations was calculated, using $\mathrm{N}_{\mathrm{CC}}$ values from measurements during periods with about the same atmospheric pressure but with outdoor temperatures as different as possible (see fig 1). Next, the correction factor for the atmospheric pressure variations was calculated, using $\mathrm{N}_{\mathrm{CC}}$ values from days with about the same outdoor temperature but with varying atmospheric pressure (see fig 2). The $\mathrm{N}_{\mathrm{CC}}$ values were corrected for the small temperature differences by means of the approximate correction factor calculated in the first step. All $\mathrm{N}_{\mathrm{CC}}$ values from 1977 were then normalized to a common atmospheric pressure $(100 \mathrm{kPa}$ $=750$ torr) and plotted in a time diagram (fig $3 \mathrm{~A}$ ) together with the corresponding outdoor temperature range during the measurements (fig $3 \mathrm{C}$ ). It is obvious that seasonal variation is in anti-correlation with the temperature. 


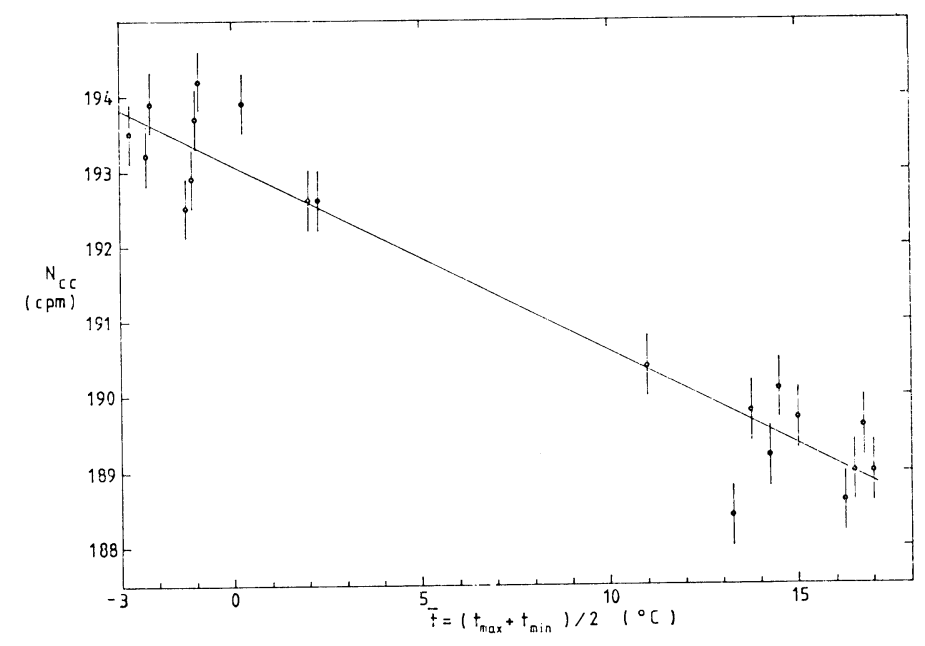

Fig 1. Coincidence counting rate $\mathrm{N}_{\mathrm{CO}}$ as a function of the "mean" outdoor temperature $\overline{\mathrm{t}}=\left(\mathrm{t}_{\max }+\mathrm{t}_{\min }\right) / 2$ during the measurement. $\mathrm{N}_{\mathrm{CC}}$ is normalized to 770torr (102.7 $\mathrm{kPa})$. Atmospheric pressure: $765<\mathrm{b}<775$ torr $(102.0<\mathrm{b}<103.3 \mathrm{kPa})$. Maximum atmospheric pressure correction $\pm 1.5 \mathrm{cpm}$. Regression line equation: $\mathrm{N}_{\mathrm{CO}}=-0.248 \overline{\mathrm{t}}$ $+193(\mathrm{cpm})$. Correlation coefficient $\mathrm{r}=-0.963$.

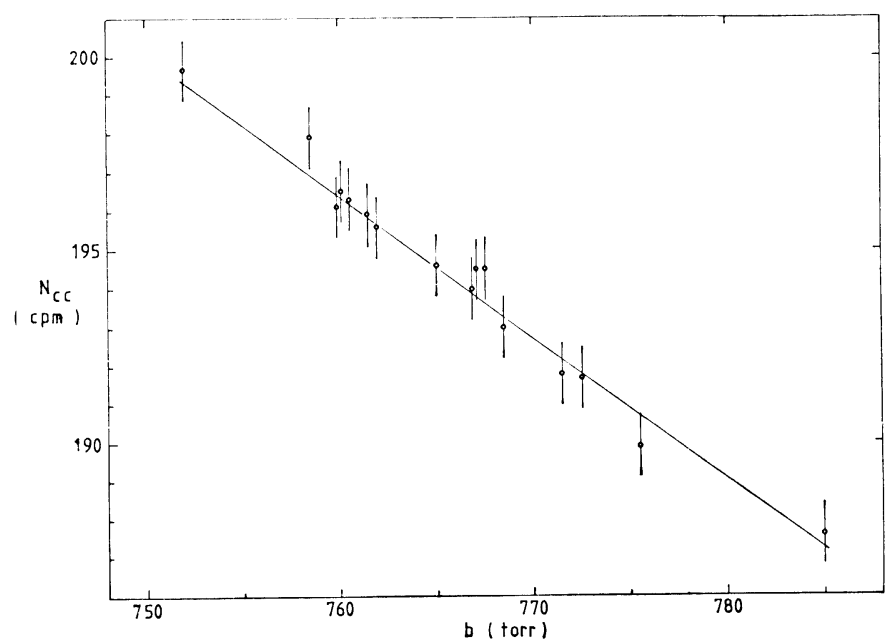

Fig 2. Coincidence counting rate $\mathrm{N}_{\mathrm{CO}}$ as a function of the atmospheric pressure $\mathrm{b}$. $\mathrm{N}_{\mathrm{CC}}$ is normalized to a "mean" outdoor temperature $\overline{\mathrm{t}}=0^{\circ} \mathrm{C}$ by means of the correction factor $-0.248 \mathrm{cpm} /{ }^{\circ} \mathrm{C}$ (see fig 1 ). Outdoor temperature: $-1<\overline{\mathrm{t}}<+3.5{ }^{\circ} \mathrm{C}$. Regression line equation: $\mathrm{N}_{\mathrm{CC}}=-0.381 \mathrm{~b}+486(\mathrm{cpm})$. Correlation coefficient $\mathrm{r}=$ -0.989 . 
A.

B.

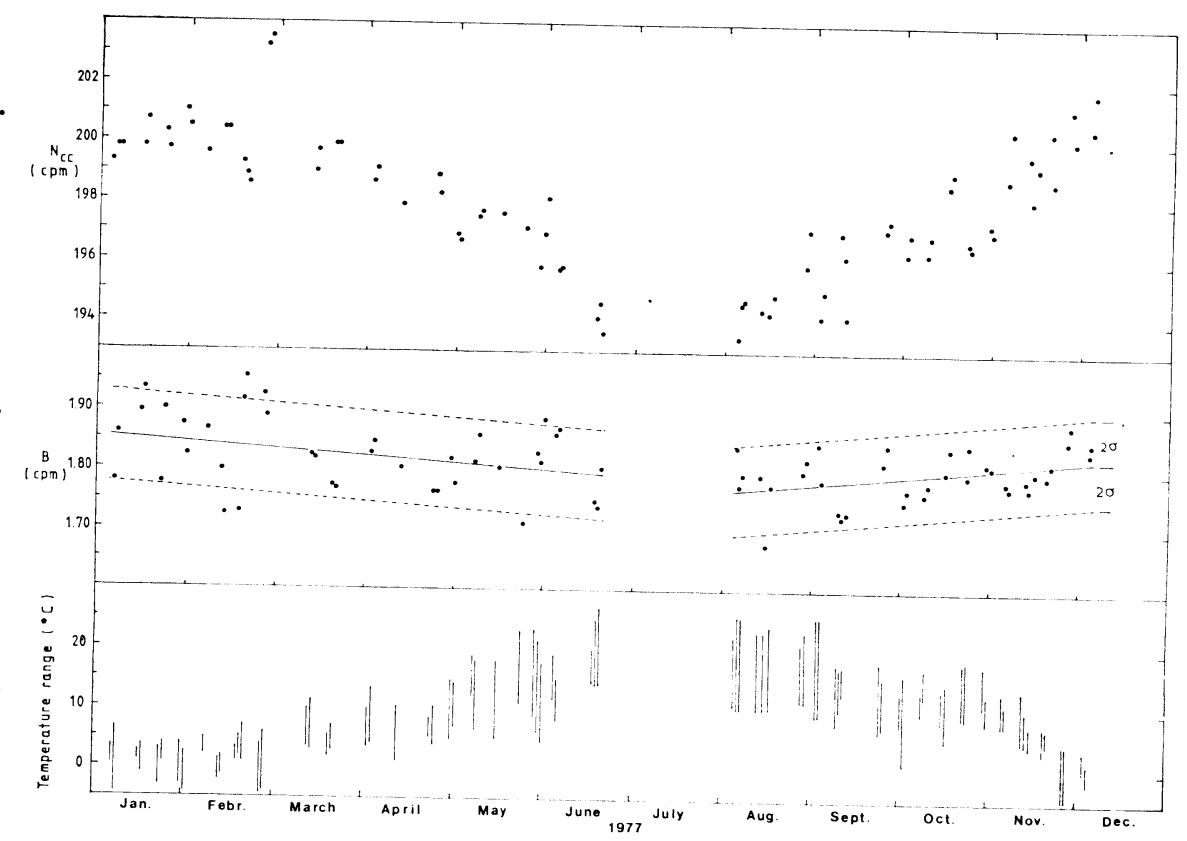

Fig 3. A) The coincidence counting rate $\mathrm{N}_{\mathrm{CC}}$ during background measurements in 1977 normalized to an atmospheric pressure of 750 torr $(100.0 \mathrm{kPa})$.

B) The background counting rate $B$ during 1977 normalized to an atmospheric pressure of 760 torr $(101.3 \mathrm{kPa})$. The dashed lines are $\pm 2 \sigma$ from the regression lines. $\boldsymbol{\sigma}= \pm 0.038 \mathrm{cpm}$ is calculated for a $21-\mathrm{hr}$ background measurement.

C) The outdoor temperature ranges during the background measurements.

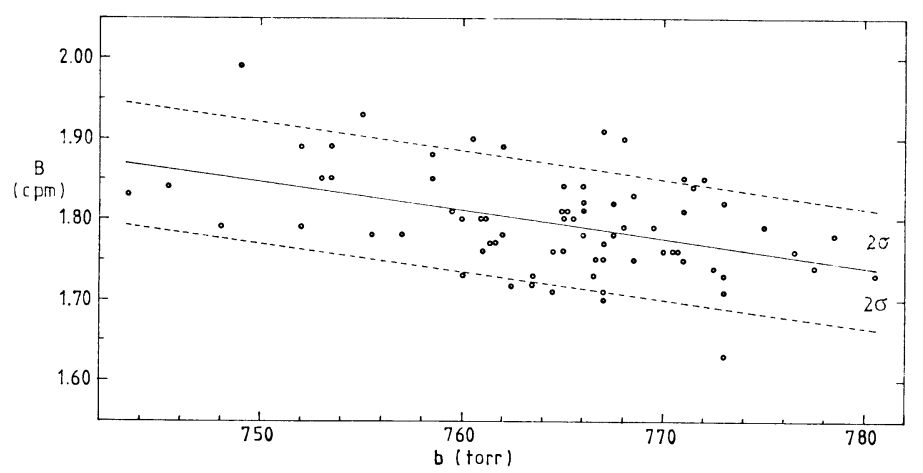

Fig 4. Background counting rate as a function of the atmospheric pressure $b$. Regression line equation: $\mathrm{B}=-0.00343 \mathrm{~b}+4.415(\mathrm{cpm})$. Correlation coefficient $\mathrm{r}=$ -0.487 . Ca $17 \%$ of the background values are outside $\pm 2 \sigma$ (dashes). $\sigma=0.038 \mathrm{cpm}$ is calculated for a 21 -hr background measurement with $\mathrm{N}_{\mathrm{CC}}=193 \mathrm{cpm}$. 
The regression line and the "Standard error of estimate"

$$
\mathrm{S}_{\mathrm{B}}=\left[\Sigma\left(\mathrm{B}-\mathrm{B}_{\mathrm{c}}\right)^{2} / \mathrm{N}\right]^{1 / 2} \text {, }
$$

measuring the scatter about this line (Arkin and Colton, 1961, p 76), were calculated for all background values from 1977 as a function of the atmospheric pressure b (fig 4), on the one hand, and as a function of the coincidence counting rate $\mathrm{N}_{\mathrm{CC}}$ (fig 5), on the other. In this equation for $\mathrm{S}_{\mathrm{B}}$ is the measured background value, and $B_{c}$ is the corresponding value calculated from the regression line equation. $\mathrm{N}$ is the total number of measurements (75). The resulting figures are shown below.

$$
\begin{array}{ll}
\mathrm{B} \text { as a function of } \mathrm{b}: & \mathrm{B} \text { as a function of } \mathrm{N}_{\mathrm{CC}} \text { : } \\
\mathrm{r}=-0.487 & \mathrm{r}=0.581 \\
\mathrm{~S}_{\mathrm{B}}= \pm 0.054 \mathrm{cpm} & \mathrm{S}_{\mathrm{B}}= \pm 0.050 \mathrm{cpm} \\
\mathrm{Ca} 17 \% \text { of the } \mathrm{B} \text { values are } & \mathrm{Ca} 9 \% \text { of the } \mathrm{B} \text { values are } \\
> \pm 2 \sigma \text { from the regression line. } & > \pm 2 \sigma \text { from the regression line. }
\end{array}
$$

$\mathrm{r}$ is the correlation coefficient; $\sigma= \pm 0.038 \mathrm{cpm}$ is calculated for a 21hour background measurement.

A comparison of the figures shows that for calculation of the actual background, the coincidence counting rate was a better parameter than the atmospheric pressure. The reason is that since the coincidence counting rate depends not only on the atmospheric pressure, but also on the temperature in the atmosphere, it reflects rather well the actual muon component and muon created secondaries reaching our counter.

All background values from 1977 were then normalized to a common atmospheric pressure $(101.3 \mathrm{kPa}=760$ torr $)$ with the aid of a correction factor taken from the regression line equation for $\mathbf{B}$ as a function of the atmospheric pressure (see fig 4), and plotted in a time diagram (fig 3B). The regression lines for the two periods January-June and August-December were calculated. It is clear from the diagram and the regression line coefficients $(-0.00036$ and $+0.00043 \mathrm{cpm} /$ day $)$ that the background values

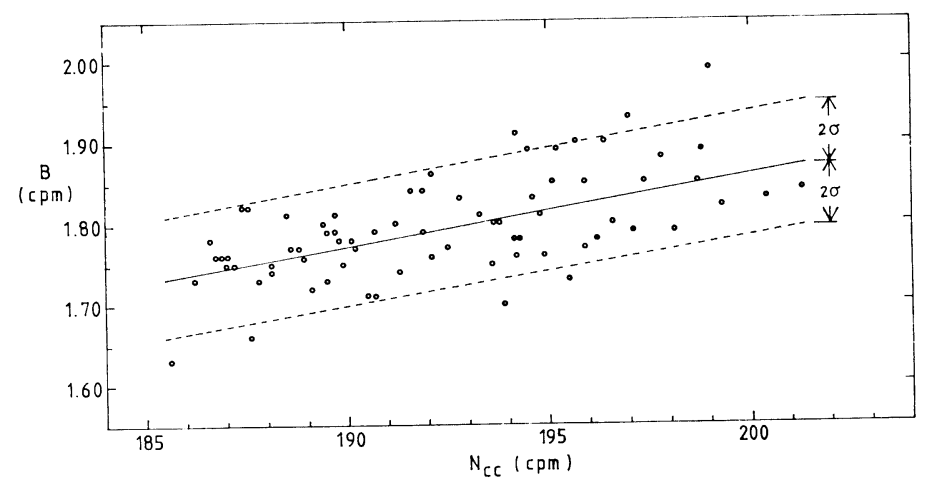

Fig 5. Background counting rate as a function of the coincidence counting rate $\mathrm{N}_{\mathrm{CC}}$. Regression line equation: $\mathrm{B}=0.00863 \mathrm{~N}_{\mathrm{CC}}+0.134(\mathrm{cpm})$. Correlation coefficient $\mathrm{r}=0.581$. Ca $9 \%$ of the background values are outside $\pm 2 \sigma$ (dashes). The value for $\sigma$ is the same as in figure 4. 
normalized to a common atmospheric pressure show a seasonal trend with higher values in winter than in summer. The calculated maximum difference is ca $0.06 \mathrm{cpm}(3.3 \%)$.

The reason for this seasonal variation of the background probably is to be found in the temperature dependent vertical extension of the atmosphere and in the short average life-time of the muons. A temperature increase in the lower atmosphere moves the zone of muon creation to a higher altitude so that a larger fraction of the muons has time to disintegrate before reaching the surface of the earth. A temperature increase in higher altitudes ( 15 to $25 \mathrm{~km}$ ) has the opposite effect. The resultant thinning of the air causes a reduced probability for the pions to interact with nucleons in the air before transformation to muons. This results in a small increase in the probability for muon creation and a corresponding increase in the number of muons reaching the earth (Ehmert, 1962, p 356). In our geographical position $\left(55^{\circ} 42^{\prime} \mathrm{N}, 13^{\circ} 11^{\prime} \mathrm{E}\right)$ the temperature effect mentioned first is dominant, according to our results. The second effect may be responsible for irregularities in the connection between the normalized background and the outdoor temperature.

Another way to check if there is a real temperature dependent difference between the background calculated on the basis of the atmospheric pressure $b$ and the coincidence counting rate $C G$, respectively, is the following:

The regression line equations for $\mathrm{B}(\mathrm{b})$ (see fig 4 ) and $\mathrm{B}(\mathrm{CC})$ (see fig 5 ) are used to calculate $B_{b}$ and $B_{C C}$ values for a whole year based on corresponding actual values of $b$ and $C C$ during background measurements. If there are no systematic differences between the calculated $B_{C C}$ and $B_{b}$, $B_{C C}$ minus $B_{b}$ versus time would scatter randomly around the value \pm 0 . The diagram in figure 6 shows, instead, a reasonably good anticorrelation between $B_{C C}$ minus $B_{b}$ and the outdoor temperature for the year 1977 .

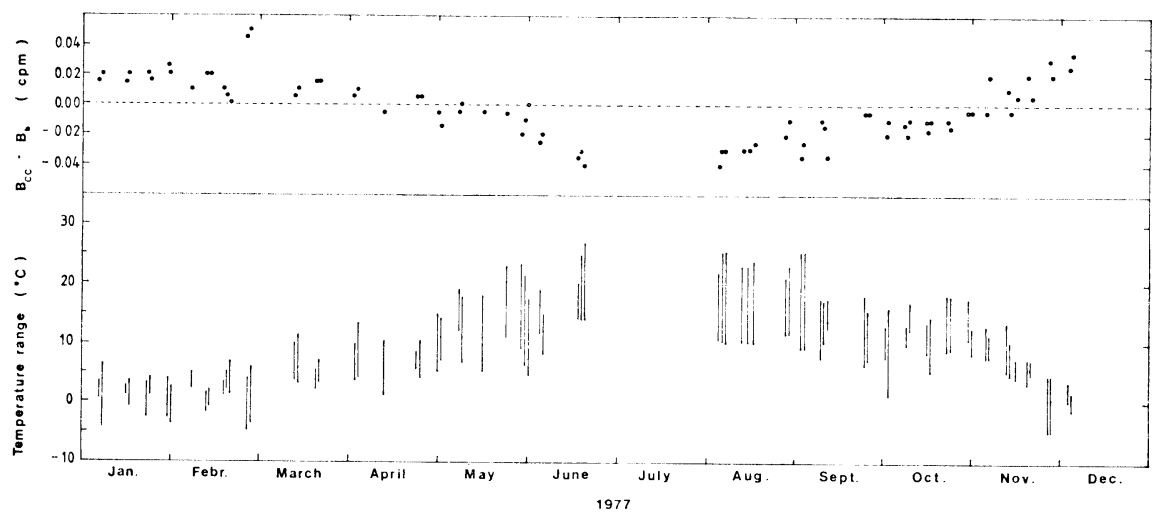

Fig 6. Diagram showing the anticorrelation between the difference $B_{C C}-B_{b}$ and the outdoor temperature ranges during 1977. The background values $B_{C O}$ and $B_{b}$ are calculated by means of the regression line equations for $B$ as a function of the coincidence counting rate $N_{C c}$ and the atmospheric pressure $b$, respectively, using the actual corresponding values of $\mathrm{N}_{\mathrm{CO}}$ and $\mathrm{b}$ for each day of background measurements. 
This confirms, without the use of normalized background values, the temperature dependency of the background. The maximum deviations correspond to ca $\pm 1 \sigma$ for a 21-hour background measurement and are, therefore, difficult to detect without suitable methods.

Finally, a check was made of the approximate consistency of the temperature effects on the background for the three years 1976, 1977, and 1978 (fig 7). The regression lines are almost identical for 1976 and 1977; the background is significantly smaller in 1978. This is partly due to a total renewal of the electrical supply system for the laboratory combined with some small improvements of the electronic equipment, but possibly also, to some extent, to the strong increase in sunspot numbers, causing a reduction of the penetrating cosmic radiation during 1978. The temperature dependency of the background is also somewhat reduced in 1978 compared to the preceding two years though it is still obvious and shows

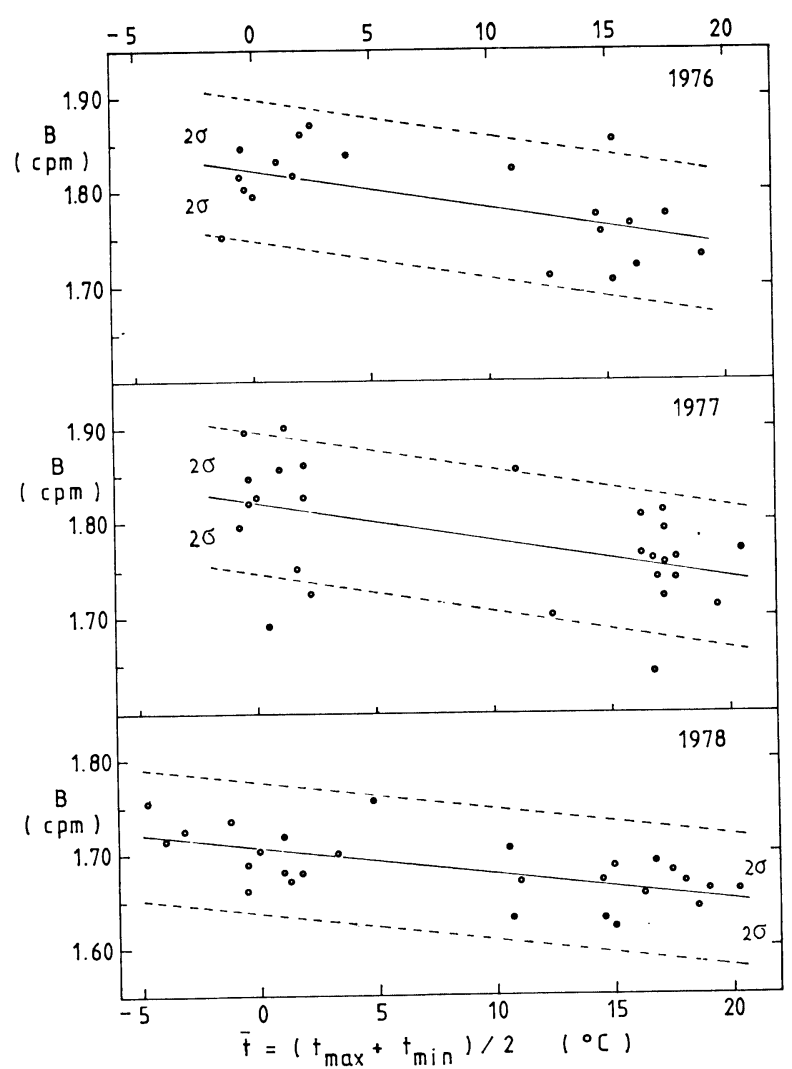

Fig 7. The approximate temperature dependency of the background in 1976, 1977, and 1978. The background values are normalized to an atmospheric pressure $b$ of 770 torr $(102.7 \mathrm{kPa})$. Only measurements with $764<\mathrm{b}<776$ torr $(101.9<\mathrm{b}<103.5 \mathrm{kPa})$ were used. Maximum atmospheric pressure correction $\pm 0.02 \mathrm{cpm}$. Correlation coeffcients: $r_{1976}=-0.566 ; r_{1977}=-0.506 ; r_{1978}=-0.634$. 
less scatter around the regression line because of the improved measuring conditions.

Arkin, H and Colton, R R, 1961, Statistical methods: New York, Barnes and Noble, Inc, $226+48 \mathrm{p}$.

Cranshaw, T E, 1963, Cosmic rays: Oxford, Clarendon Press, 125 p.

Ehmert, A, 1962, Die Kosmische Strahlung in der Geophysik, in Israël, H and Krebs, A, eds, Nuclear radiation in geophysics: Berlin, Springer-Verlag, p 343-385.

Grootes, P M, 1977, Thermal diffusion isotopic enrichment and radiocarbon dating beyond 50,000 years BP: Thesis, Univ Groningen, $221 \mathrm{p}$. 